\title{
The values of pallets: An ethnography of exchange in the warehouse of an Italian supermarket
}

Journal of Material Culture

(C) The Author(s) 2016 Reprints and permissions: sagepub.co.uk/journalsPermissions.nav DOI: I0.1।77/I359|835|6662674 mcu.sagepub.com

@SAGE

\section{Edda Cecilia Orlandi}

University of Milan, Italy

\begin{abstract}
Based on ethnographic research carried out in an Italian supermarket, this article discusses the role of European Pallet Association (EPAL) pallets as especially valued objects in the social economy of its warehouse. Pallet exchanges and the processes of value conversion they entail are framed in the context of the supermarket as a workplace where the connecting and individualizing elements of exchange relationships are analysed. Pallets travel around in a commodity context where the value of things is equated with their price. Yet, participation in pallet exchange allows for the creation of a community of practice between warehousemen and drivers, as well as enabling them to establish their distinctive roles and status as men whose work has to do with the 'making' of commodities.
\end{abstract}

\section{Keywords}

ethnography, exchange, pallets, supermarket, value

\section{Introduction}

This article draws inspiration from a point first made by Strathern (1988: 180) that in exchange and the processes of value conversion it entails there is much about separation as well as connection, separation being "intrinsic to the ability to perceive ("personify") relations'. This perspective complements the commonplace starting point in contemporary anthropological reflections on value: Munn's (1986: 3) definition of value as an act's expansive capacity, and her focus on the processes 'through which a community seeks to create the value it regards as essential to its communal viability'.

\section{Corresponding author:}

Edda Cecilia Orlandi, Dipartimento di Scienze Sociali e Politiche, Via Conservatorio 7, 20122 Milan, Italy.

Email: edda.orlandi@gmail.com 
If the materialization of relations through specific forms of exchange as a key process in understanding value creation has been widely explored in Melanesian ethnography, here I am employing this idea in order to make sense of ceremonial exchanges taking place in a completely different setting: the warehouse of a Western European supermarket (in Milan, Italy). Processes of value creation and conversion have been explored in shopping places such as supermarkets in respect of their role in consumers' provisioning (Miller, 2001) but to extend the investigation of such processes to the supermarket's warehouse is to enter unknown territory. Yet warehouses are equally sites where objects flow in different directions and are transacted in different forms, so multiple and complex processes of value conversion and patterns of ceremonial exchange can also be found there.

The ethnographic material I present is based on my observation of the exchange of pallets between truck drivers and the warehousemen of the supermarket where I carried out my research examining processes of value creation and destruction. ${ }^{1}$ Pallets are platforms (usually made of wood) used to transport most of the goods that travel from producers to warehouses and stores. ${ }^{2}$ Like the containers described by Levinson (2006), pallets are a key component in what Urry (2007) has called 'mobility systems'. They are objects that make the global flow of commodities possible thanks to the standardization and integration of the infrastructure for expanding globalization allowed by containerization. This process prompted major changes in workplaces relations, disrupting existing patterns of social relations at work and creating new patterns of relations there (Parker, 2013: 370-371). In this respect, containers used to transport commodities are shaped by and sustain ways of organizing work, trade and systems of transportation (Bevan, 2014) which are likely to require some work of negotiation, adaptation and bargaining in the different contexts they move through. Indeed, pallets share with any transport container the feature of being in mobile relations with multiple places, artefacts and persons, which in turn makes them objects to which changing cultural and economic values are assigned (Parker, 2013: 369). In this respect, Munn's $(1977,1986)$ detailed analysis of the transformations involved in the making of Gawan canoes exemplifies how transport artefacts do not only allow trade, but may be themselves vehicles through which value is created. Their construction starts a cycle of outward transformations that makes them valuables, and makes them bring back more valuables.

Pallets also emerged as especially valued objects in the social economy of the warehouse. Exactly like Gawan canoes, pallets are constructed as valuables through a complex web of labour relations and exchanges. The pallet economy is built around exchange and the creation of value. It establishes demarcation lines between the exchangers and constitutes the material foundation for a set of social, economic and aesthetic evaluations, even in such an apparently impersonal 'rational' marketplace/workplace as a contemporary supermarket.

Participation in their exchange helps to establish not only the respective roles of warehousemen and drivers in their workplace but also the creation of a shop-floor culture in which these workers can operate as men whose work has to do with the 'making' of commodities. Each group is thus the bearer of a distinctive interest which contributes to the overarching warehouse community.

Looking at pallet exchange from this point of view, this article is intended as a contribution to the study of exchange seen as a social fact that can shed light on broader processes 
and relations than the act in itself. Namely, I am investigating pallet exchange as a way to illuminate labour processes that create persons and build up a workplace community.

In the following section I set out the analytical framework which helps to make sense of the value attributed to pallets. Then I describe their nature as valuable objects, the ways in which they are transacted and the creation of relations on the basis of those exchanges. Subsequently I frame pallet transactions as practices that turn the supermarket into a workplace where the value created through exchange and the values created through labour are converted one into the other. I conclude with an analysis of these conversions of value into values through pallet exchange - their transformation from objects prized for their price to objects that condense moral value. I am arguing that the value of pallets is apparently sustained by their economic worth but is in reality founded upon the relationships built around them and the culture of labour they embody.

\section{The value(s) of reciprocity}

The idea that reciprocity goes with equivalence, and equivalence with equality, has long been acknowledged: the exchange of equivalent objects makes the partners in the transaction equal (Forge, 1972: 533-534; Mauss, 2004[1924]: 258; Myers, 2001: 14). Yet reciprocity is also about finding ways to delay and disguise equivalence, since the restoring of equality implies complete independence, thus the possibility to call an end to the relationship (Bourdieu, 1972: 222-223; Graeber, 2014: 71). When there is no obligation to reciprocate left, there is no obligation to renew social bonds either. Subtle ways to create imbalance in a balanced exchange that would otherwise create no social relationship (or close it) are thus to be found in transactions that are meant to be continued. Deviations from equilibrium are what should be looked at, according to Sahlins (1976: 127), to understand the connections between reciprocity, social relations and materiality. If 'exchange is a process that holds a system of power relationships in balance' (Weiner, 1989: 227), this balance is achieved in a 'process tending towards equivalence' without reaching it (Graeber, 2014: 71; see also Forge, 1972: 535; Munn, 1983: 282; Strathern, 1988: 304). The constant work of balancing - in the timing, quality and quantity of what is exchanged - opens the exchange relation towards the future. This never-resolved tension accounts for the ongoing renewal of gift-like transactions.

The delays that characterize gift-giving also open the exchange relationship to all sorts of possible tricks and opportunism, as well as being the source of its strength due to the mutual commitment to trust they presuppose (Bourdieu, 1972: 222-223; Sahlins 1976: 203). Cunning, deception and disappointment in obtaining a coveted shell are a constant preoccupation in kula exchange itself (Malinowski, 1978[1922]: 73; Munn, 1986: 64).

Indeed, the absence of the ambiguity between equivalence and imbalance is supposed to characterize commodity exchange in its purest form, one-off transactions between strangers. These kinds of exchanges are, however, almost non-existent in practice, even in our lives as consumers and workers in advanced market economies. As consumers, we are assumed to be involved in impersonal, definite dealings - we take, we pay, and that is the end of it - but are also expected to invest emotionally in loyal relationships with the brands and stores that provide the goods and services we purchase (Foster, 2011). As 
workers, in spite of the need of competitive businesses for disposable, on-demand employees, we are nevertheless supposed not to abandon the workplaces that have 'invested' in our training as professionals and to feel loyalty and commitment towards them (Breen, 1997).

Starting with Appadurai (1986), the acknowledgment of this interweaving between gift-like and commodity-like logic in actual exchanges has provided, among many fruitful lines of research, insights into the functioning of corporations and the study of the global flows of goods they deal with. In this respect, the exploration of the multiple ways in which the concepts of gift and commodity exchange intersect also leads to questions about how quantitative and qualitative value are created in transactions and about how value as the worth-price of a commodity and value(s) as what defines our relationships with other human beings are themselves related. Explorations of the complex ways in which qualitative value is converted into quantitative value and vice versa (Crăciun, 2015; Cross, 2014; Foster, 2011, 2013; Miller, 2008; Tsing, 2013) show that commodities may gain value through processes of value transformation from non-market transactions, both material and immaterial, throughout all their social lives and movements. Conversely, social relations and moral evaluations play a crucial role in the creation of economic value through market transactions. These enquiries account for the depiction of capitalism as a system in which economic evaluations are shaped and sustained by the incorporation of social relations that often work in unpredictable ways in defining how value is created (or destroyed).

Contributions of that kind have often taken as their starting point Munn's (1986: 9) definition of value as an act's expansive capacity, that is its capacity to extend 'a spacetime of self-other relationships formed in and through acts and practices'. From this perspective, value is intended as a creative capacity of transformation of self and the recipient's self through their relation. The production of positive value involves first an externalization, thus a separation of internal elements (p. 6), and a subsequent re-incorporation. This process leads to the creation of an intersubjective relation: practices are thus understood as forming social relations and the actors engaging in them. In this respect, exchange is understood primarily as an activity that creates connections, and value is the result of actions of consequence in extending bonds and relations. ${ }^{3}$

According to Strathern (1988), however, the concepts of separation and detachment are equally important in understanding the outcomes of exchange. She points out that, in order to have a relationship, the parts need to be perceived as differentiated partners. The gift relationship is what separates the interests of donor and recipient, creating them as differentiated subjects (p. 183). Moving from the Melanesian context, we can see the same process operating when gift-like transactions are carried out in commodity contexts, leading to the creation of persons out of undifferentiated, impersonal economic actors. The idea that separation, the establishment of differences, is what is created in exchange - that is, the creation of distinct individuals who perform their relations through exchange - has been recently explored by Cross (2014) in analysing corporate gifts. His analysis suggests that such a perspective can challenge conventional notions of hierarchy and power inside corporations, because it illustrates how workers' actions and capacities are materialized and made visible in these gift relations. In what follows, I argue that, in this respect, exchange relations among workers can be analysed in the same terms. 
Connection and separation are indeed the two cornerstones that underpin the imbalanced equivalence of reciprocity in exchange. The old paradox of gift-giving pointed out by Mauss (2004[1924]), that gifts and counter gifts are somehow voluntary yet compulsory, accounts for the same tension between the building of bonds and the building of equal (thus virtually independent) persons occurring in reciprocal exchange. Following Munn (1986), we can understand the connecting elements of exchange as part of what constitutes communal viability for a community (p. 3) and self in relation to others (p. 15); while the element of separation stressed by Strathern (1988) points to the individualizing of persons as a process resulting from the relationships created in exchange. I shall use this framework to depict the participation in the cycle of pallet exchanges as a way to create relationships out of transactions in which quantitative value is converted into qualitative value. The pallet exchanges allow for the creation of a community of practice (Lave and Wenger, 1991) between warehousemen and drivers, as well as enabling them to establish their distinctive roles and status as workers.

\title{
Exchangeable and non returnable pallets
}

June 2008

\begin{abstract}
I have been in the supermarket for a couple of months now and I spend most of my mornings hanging around the back of the warehouse, chatting with people, asking if they need help, looking at the flow of things that enter and leave the supermarket. I am sitting on a little pile of pallets and I am taking pointless notes. The workers of the supermarket like that I am writing about them and find this activity extremely funny, thus I write on my little notebook now and then, so as to fit the role of 'writer' I have been assigned to. I see that one of the warehousemen is operating the forklift, so I instinctively stand up, anticipating he is coming towards the pile in order to take some of the pallets and give them to the truck driver. Another warehouseman, however, warns him that the pallets brought with this load are non-returnable and he does not need to give back any to the truck driver. In Italian, non-returnable translates as ' $a$ perdere' (literally 'to be lost'). This passing remark makes the pallets I have ignored so far a suddenly interesting object of inquiry. To be sure, I have seen many times pallets to be delivered and returned, but the fact that some can be 'lost' (thrown away) and some are to be returned makes me realize now that some sort of value should be assigned to the latter.
\end{abstract}

It turned out that I was right. Some pallets ('exchangeable' pallets) do 'have' value, while others (non-returnable, disposable ones) do not. This is what everyone told me when I asked about the difference between the two. What makes pallets valuable or not, then, are the forms of their circulation.

Exchangeable, 'valuable', pallets are those marked EPAL(European PalletAssociation), a European standard regulating their production and technical features. Those were the majority of the pallets delivered in the supermarket and are also the prevailing ones used for transportation of mass market products (Dallari and Marchet, 2010: 3). These pallets are marked with the EUR-EPAL logo, their date of production, the symbol of the railway of the country where they were approved as fitting the standards, and are assembled with special nails. The EPAL association also set out a list of rules to be followed when repairing them and defines which kind of damages can be repaired in a way that does not affect 
their status as 'original' EPALs, or not. As their name suggests, EPAL exchangeable pallets always need to be returned. When a truck driver delivers his truck's load, he is given back the same number of pallets he has delivered. Obviously he is not given back exactly the same objects, since they still have commodities on them, but other empty pallets kept in the deposit.

Non-returnable pallets, instead, are kept in the place where they are delivered. If they are in bad condition or weak, they are usually thrown away. Otherwise, they can be employed for storage. In the supermarket chain where I carried out my research, nonreturnable pallets were painted yellow (so as to be clearly recognizable) and kept for storage inside the deposit. They needed to be made recognizable because many of them were EPAL pallets that had been damaged and then repaired in such a way that made them non-exchangeable according to the guidelines of EPAL. The previous life of those pallets as exchangeable (valuable) ones, however, seemed not to be perceived by the warehousemen, who considered non-returnable and EPAL pallets as entirely different kinds of objects. When I dared to mention that, actually, yellow pallets were EPAL pallets, I was immediately corrected by an amused worker, who could not possibly understand my stupidity and ignorance after all my questioning about those objects: 'nooo, the yellow pallets are the non-returnable ones!'. This failure to recognize non-returnable pallets as previous exchangeable ones (in spite of blatant evidence) is consistent with the treatment and description of EPAL pallets as if they were eternal. As a matter of fact, the life-cycle of an EPAL pallet is estimated as up to 7 years, but most of the pallets I saw in the supermarket had been built no more than 3 or 4 years before. My observations are consistent with results of a research suggesting that, on average, EPAL pallets that circulate in large-scale retail get lost two years after their purchase (Dallari and Marchet, 2010: 8). Nevertheless, both the workers of the supermarket and the drivers took care of EPAL pallets and spoke of them as if they were precious objects to be preserved in the long term. This contradiction between the short life of these things as daily work tools and the discourses surrounding them as eternal stores of value is explained by their involvement in transactions that confer prestige to those involved in the trade. When they are thought of as the prizes of these peculiar tournaments of value (Appadurai, 1986), pallets become eternal, valuable objects, things that incorporate enduring social values.

A further kind of pallet circulating in the supermarket that has to be returned are the so-called 'rented pallets'. Painted blue, they are owned and managed by Chep, ${ }^{\circledR}$ a company that provides pallet and container pooling services. Although they have to be returned, these pallets are not valuable in the eyes of the workers involved in their dealing. As a matter of fact, the value of EPALs is explained by warehousemen with the existence of a black market of stolen pallets that allows truck drivers to make extra money from their work. This is why rented pallets are 'not valuable': because they always remain the property of the firm providing the pooling services. It does not make sense to steal them because whoever is in possession of them is just a provisional holder, not their owner. Instead EPAL pallets can be sold as second-hand pallets on the black market. The interactions between warehouse workers and drivers concerning EPAL pallets are thus best described as an ongoing 'cops and robbers' game, in which the drivers try to steal the pallets and warehouse workers watch them (but can sometimes be complicit). 
In the making of pallets as valuable objects, however, the money made in this illicit trade counts only as part of the explanation. Pallets embody both quantitative and qualitative values. They are not only stores of value but also stores of values. This is consistent with their being spoken of as objects that can be more or less 'good' and 'beautiful'. As a matter of fact I witnessed several confrontations between supermarket workers and drivers concerning the comparability of the 'beauty' of the pallets they were receiving and returning. In principle, EPAL pallets are equivalent objects: any pallet should be exchangeable with any other one, provided that it is not damaged. In practice, however, the workers involved in their exchange insisted that a 'beautiful' pallet should be replaced with an equally 'beautiful' one (that is to say, a pallet that looked 'new', without regard to its actual manufacture date, stamped on it). Lengthy discussions were sometimes held about the debatable comparability of beauty between two pallets or piles of them. Features taken into account in this respect were absence of little cracks in the wood, its smoothness (how much the wood splintered) and the fact that the colour was not darkened.

The more 'beautiful' the pallet, then, the easier it is to exchange it. The aesthetic appreciation of the object, which in turn is a requirement for its circulation, is an essential part of its evaluation. Exchangeability is also what makes pallets 'good' or 'bad': a good pallet is a pallet that can be exchanged with another one. The warehouse workers stated that, actually, some of the pallets they exchanged were not real EPAL pallets but counterfeit ones. Thus their strength was not certified. However, the fact that some pallets were recognized as counterfeit did not make them less good, as long as they could be exchanged like 'real' ones (that is to say, if at first sight they looked 'good'). According to Lemon (1998) and Jamieson (1999), counterfeit objects, in spite of being recognized as such, can be deemed valuables when they take on the value of the originals as objects that embody cultural as well as economic worth. In both these examples, the aesthetic appreciation of the object, which in turn is a requirement for its circulation, is an essential part of its evaluation. This is also the case for pallets, whose cultural and economic worth lies in their exchangeability.

\section{Ways to acquire pallets (and to let them circulate)}

As mentioned, pallets are at constant risk of being diverted from regular routes to the black market. In order to sell them in this market, drivers need to find ways to appropriate more pallets than those they deliver. There are three ways in which drivers can obtain surplus pallets from the warehouse workers: thefts, corruption and gifts. Each of them requires peculiar skills and an ability to establish an antagonistic but trustworthy relationship with their counterpart.

According to the warehouse workers, every truck driver was a trafficker of pallets. At best, for some of them, the assumption that they were constantly trying to steal pallets could be suspended for that particular store where they were well known and 'friends' of the warehousemen. However, they were deemed not to be completely trustworthy in any case. Explicit confessions of drivers involved in the trade, however, were rare (and usually referred to the past). The following conversation is typical of my first enquiries about the value of pallets among truck drivers: 
Me: $\quad$ How much is the value of a pallet?

Driver: It depends on what's on it ...

Me: $\quad$ No, I mean, an empty one!

Driver: Oh, but I have never done that kind of thing!

Me: $\quad$ Oh, but you must know, what do people ...

Driver [before I even finish my question]: It's 5 euros.

At first, truck drivers denied they knew the value of the pallets, as if this knowledge could be taken as a confession of being involved in their illicit trade. They stated they assumed EPAL pallets had some value because they were asked to bring them back. Then, when I insisted they must know, thus making them realize that I knew, they immediately (and invariably) answered it was 5 euros, the standard price they got for a 'second-hand' pallet on the black market. The fact that they first denied knowing the value of pallets and after my not particularly pressing insistence promptly provided a defined price reveals their attitude towards the supermarket workers. On the one hand, they wanted to present themselves as trustworthy partners. On the other, they needed to subtly signal they were inside the trade, as a way both to affirm their status and to convey their willingness to possibly agree on a deal with the warehousemen.

Trustworthy drivers could be allowed to take back pallets by themselves instead of having to wait for the warehousemen to handle them. This would result in a quicker delivery but, most importantly, permit choice of the most 'beautiful' pallets. Also, it would possibly result in the theft of one or two more. Trust is essential to be able to steal pallets, taking advantage of the more relaxed attitude of the warehouse workers towards the drivers they consider friends. Thus, trust built during years of interplay between warehousemen and drivers is fragile and easily betrayed. One of the warehousemen reported his discovery of a pallet thief in these terms:

It happened: he came, I keep the pallets here, he took the whole pile, with nonchalance, and put it into the truck. Got everything, closed everything, and went away ... You did that? Wait a minute ... besides I had known him for ages, it was such a poor move. Then, we remained friends, because no-one ... I mean, you tried it, you didn't make it ... but I am sure it has happened and I haven't realized, one day or the other ... not many times, but still ...

It is assumed that drivers are always looking for opportunities to steal pallets and that they sometimes succeed. Moral blame is attributed to this attitude only when the theft is discovered.

In fact, establishing one's own fame as a pallet-trader is nevertheless equally important, not only because this is what the game is all about, but because corruption is one of the strategies to acquire pallets. I was very proud to be offered (only half-joking) such a deal - 20 euros for a pile of 16 pallets to disappear - only to discover that the driver was trying to take advantage of my naivety: having heard the conversation, the chief warehouseman promptly made clear to the driver that he should have offered 40 , since this was half of the profit he would make.

The one serious attempt to corrupt a warehouseman I witnessed, however, did not involve money. The offer was a cigarette carton: prestige goods in exchange for other 
prestige goods. That warehouseman estimated the gains obtained in his involvement in such a deal not worth the risk, but I was constantly told legendary stories of colleagues (as well as drivers) that, 'in the past', had become rich, had 'bought a villa', thanks to the illicit pallet trade. Such fortune was deemed nowadays unattainable by the warehouse workers for themselves, due to the increased surveillance, but still feasible for drivers, who, in turn, liked to let the workers of the supermarket think it actually was the case.

Stealing pallets, however, is not easy, due to their bulk and the careful supervision they are subject to. Convincing a warehouseman to enter a deal could be tricky as well, and it would also imply dividing the profits between the two partners.

Obtaining gifts of pallets is a third, smoother, option for acquiring them. The giftgiving would work this way: the warehousemen would give back to the driver, together with the amount of EPAL pallets he had brought in, one or two more - damaged. This way he could sell the 'good' extra pallets he was given and keep the broken ones in case he would need to claim, when confronting the possible complaints of his employer, that the pallets had broken during transportation, or that he had not realized they were damaged when he was given them.

Far from resembling the model of impersonal economic exchange dominated by closed reciprocity (Graeber, 2001: 219-220) it is supposed to follow (one pallet given, one pallet received), the exchange of EPAL pallets involves much relational work (Zelizer, 2012) and subtle negotiation. The stated aim is the acquisition of pallets to be sold on the black market so as to make extra money. However, it seems implausible that drivers can really 'become rich' thanks to their skills in acquiring pallets, considering all the efforts and schemes put in place in order to acquire even a handful of them. The constant evaluations of pallets as more or less good and beautiful point to the fact that their value is not reducible to their economic worth.

The supermarket warehouse workers are engaged in the effort to keep the EPAL pallets in the regular circuit (as opposed to the drivers who want to drain them towards the 'second-hand', illegal one). In this respect, taking care of the pallets they receive and return is a key element of 'doing a good job' for the supermarket workers. They tried to keep the best ones and sometimes took pride in having successfully returned 'ugly' pallets in exchange for 'new' ones to some disagreeable drivers (that often meant foreign, non-Italian speakers). This sense of attachment is exemplified in the question one of the warehousemen used to ask drivers every time he was returning the pallets: 'how many are you stealing today?' (that is, how many he should return).

Yet, they do not want to keep too many pallets either. For example, drivers employed by the same supermarket chain (travelling from the regional storehouse to the supermarket) would occasionally ask if they could have their pallets returned at the next delivery. The request was usually motivated by the fact that they already had an overloaded truck. This was considered extremely annoying by the warehousemen, who referred to this circumstance as 'being put in debt'.

Warehouse keepers have a tricky role in pallet exchange. On the one hand, there is a sense of moral blame for those colleagues bribed for letting the drivers steal large amounts of pallets in their workplaces. I was told the story of a previous chief warehouseman in that supermarket, who had been made redundant for those thefts in terms of someone who had received a deserved punishment (even if part of his blame was having 
been as stupid as to be discovered). On the other hand, warehouse workers are participants in this subculture they contribute to creating and sustaining. In fact, taking part in this game is an essential part of the worth of their job, part of what makes their work meaningful to them. They do so by keeping pallets in the legitimate circuit but also sometimes letting some of them go. This clearly resonates with Weiner's (1989) keepingwhile-giving argument. Pallets, however, are never singularized to such an extent that they become non-exchangeable.

\section{The making of a workplace through pallet exchange}

In discussing pallets, one of the warehousemen compared them to stamp or coin collecting, practices that involve both circulation and accumulation of valuable objects and a specific knowledge about them. The practices and discourses surrounding pallets have in common with collecting the 'learning and playing by the rules of the game' that help the collector 'gain a sense of mastery and competence', as well as the development of 'a sense of fellowship with fellow-collectors' (Belk, 1995: 150-151). The qualitative appreciation of pallets described previously shows that participation in these exchanges requires an aesthetic knowledge of the objects as well as mastery in the art of managing the dealings, acquired by experience of the game. This constitutes a common ground that allows for the building of a community of practice between drivers and warehousemen who share the same work culture and values. The moral grounds of this commonality stand in tricky balance between trust and acknowledgment of one's cunning in taking advantage of it.

However, EPAL pallets were more often compared to currency or to bank cheques. In this respect, workers were keen to point out that the 'value' of EPAL pallets came from their price. They refused the idea that there could be also a 'symbolic' value attached to them. ${ }^{4}$ When asked explicitly about the value of pallets, their market value, in the workers' discourses, stands in opposition to any other value, consistent with the assumption that market exchange is a morally free arena. This is also what justifies the notion that it is fine to steal pallets as long as you are not discovered. In practice, however, it is around the pallet trafficking and commerce that a culture of labour and work values are affirmed.

The warehousemen interpreted my tentative questions about the 'symbolic value' of pallets as my questioning about some sort of 'affective value', which they strongly rejected. This resonates with their depiction of the warehouse as a place where rational actors are busy in maximizing their interests while doing their job - which consists of making commodities circulate. In fact, warehousemen in the supermarket see their job as a matter of making commodities available for consumption and pallets are essential work tools that embody the 'practical side' of their job (the 'real', material one, as opposed to abstract paperwork). This practical side of the job, however, is also embedded in thick social relations, firstly between people and things, and consequently between people. These relations are denied in the depiction of pallets as precious merely because they are marketable objects, but are built in everyday practices and chats around pallets.

The chief warehouseman explained:

Yes, I am a little embarrassed to say so, but I am fond of pallets. I like them. Pallets are beautiful, I like to recognize as EPAL or not from a distance. I like my job. I like to look at the commodities, 
the boxes, to see where they are from ... I almost never look at the value of what I receive. I look at the boxes, the commodities themselves.

Pallets embody the physical tasks required in the job, the dealing with materiality. In this respect, the importance of pallets as work tools that embody the value of labour is also revealed in their being commonly used as a practical unit of measurement for work by the employees of the supermarket themselves: how many pallets are still to be received by the end of the morning, how many have been 'done' (that is, their content transferred on the store shelves). These tasks were contrasted with those they scornfully referred to as the 'secretary's work' they had to accomplish, that is, the paperwork involved in the deliveries. After having received the pallets and checked the correct amount had been returned, the warehousemen inevitably complained about this paperwork and often tried to leave it to a younger colleague who might be around. Signing, stamping, checking invoices and documents were considered burdensome because they were abstract, not real work. Instead, dealing with pallets epitomizes the 'really doing things', the physical labouring Willis (2000: 104) associated, in working-class culture, with the expression of 'aggressiveness; a degree of sharpness and wit; an irreverence that cannot be found in words; an obvious kind of solidarity'. The competitive subculture of pallet exchanges exemplifies this relation with materiality and its role in the building of social relations. In this respect, my interest in pallets was greatly praised but remained puzzling, being myself 'from the university' (thus in the trade of abstract knowledge). ${ }^{5}$

Participating in the pallet-trading culture allows the warehousemen to stand on an equal footing with the drivers in their respective roles of workmen who 'make' commodities - make stuff available on the supermarket shelves. The strategic position of the drivers who are in control of the pallet flows (and can profit from them) is counterbalanced by the warehousemen's gatekeeping strategies and occasional display of magnanimity in returning pallets.

Reciprocity, as a recursive process tending towards equivalence and equality, is an essential feature of the interplay between drivers and warehousemen. The odd deviations from equilibrium in quantity or quality of the pallets delivered and returned equates them as partners in a circle of reciprocal exchanges. Relationships created out of these pallet exchanges make the warehouse of the supermarket into a workplace where they confront each other in a game whereby they are particularized as persons holding a reputation of trustworthiness, artfulness, skilfulness in the trade and in their respective jobs. They are thus personified as independent partners in a cycle of exchanges in which gift-giving patterns emerge: 'the effect of these relations is to particularise individual persons by virtue of their specific ties' (Strathern, 1991). The effect of these relations is also the separation of these workers from the companies they work for.

From Melanesian ethnography, we are used to seeing how exchange may condense and embody labour and relationships. Both Munn and Strathern have been preoccupied with the analysis of the ways in which exchange is framed in wider practices and relations involving a labour of transformation. Used as we are to seeing commodity exchange in marketplaces through the lenses of Marxian alienation, we are less prepared to recognize how the process of separation resulting from exchange relations in a workplace (cf. 
Carrier, 1992) can be what actually makes workers persons, rather than being necessarily ascribable to a process of depersonalization.

In these pallet exchanges, warehousemen and drivers are independent agents who deal in pallets and play a game that lies outside the tasks they are required to perform as employees (the transaction of pallets in one-off exchanges). Yet pallets come to embody the value of labour and the relational skills displayed in managing pallet exchange lead to establishing one's reputation and prestige in the workplace. In that way, pallet exchanges also create bonds that constitute a community of practitioners who share a common work culture. The materiality of pallets in this respect plays a central role in the making of the warehouse as a site where the 'really doing things' central to workingclass culture of labour is performed and in the turning of the supermarket from a marketplace into a workplace: from a site where commodities are exchanged to a site where things and persons are constructed out of labour processes.

\section{Conclusion}

Pallets convey both quantitative and qualitative value. Each of them should be perfectly exchangeable with any other and be sold at a fixed price. Nonetheless, pallet exchange sustains sophisticated moral and aesthetic evaluations that refer ultimately to the meaning of work and work relations.

The tricks, the jokes, the doubts and the agreements made around pallets shape the drivers' and warehousemen's interplay so that it develops into a cycle of reciprocal exchanges rather than a series of one-off transactions. Pallets are valuable because they make relations. However, pallets are also valuable because they can be stolen and sold so that profit can be made out of them. The framing of pallet dealings as commodity relations sustains the definition of pallets as valuable objects consistent with the commodity context they pass through (Appadurai, 1986: 15). In fact, the exchange of pallets takes place against a cultural background where 'objects of people's relations with one another appear to be things' (Strathern, 1988: 177) rather than 'social relations being the objects of people's dealings' (p. 172). In the world of commodities that is the warehouse of a supermarket, every transaction is framed first as a commodity relation. As a consequence, references to money and market-like relations are constantly affirmed as the only legitimate ways to define value, even when everyday practices contradict the profit-seeking that is supposed to inform them.

As a matter of fact, the different interests warehousemen and drivers display in keeping pallets in the regular circuit or diverting them towards the illegal one are not reducible to the mere counting of pallets delivered and returned. The antagonistic relationships interwoven around pallet dealings allow for the personification of the workers involved: the gaining of a reputation as a trustworthy yet astute partner, someone to make agreements with, to respect and to make fun of. Pallet-trafficking constitutes, in this respect, an interesting example of the complex ways in which 'ethical and economic value gets worked out as people engage in illegal practices' (Panella and Thomas, 2015: 5).

Constant ambiguity between trust and betrayal is the main feature of these relations. This ambiguity accounts for the connections (the building of a community of practice) and separation (the building of equal, free partners) produced in these exchanges. In this framework the subterfuges and tricks played in pallet exchange open and sustain the 
personifying relations which, in turn, sustain the building of a communal work culture in the warehouse. At the same time, the discovery of a theft of pallets would put an end to these relations, resolving the tension between commonality and the pursuing of opposite interests by drivers and supermarket workers. This would precipitate them towards the commodifying, profit-seeking dimension of exchange, breaking the (slightly) imbalanced equivalence that sustains these relations.

Pallets travel around in a commodity context where the value of things is equated with their price. They also travel in a work environment where labour is about doing things and not about doing relations. Pallet exchange conveys values (in the sense of what defines our relationships with other human beings) that contradict these assumptions, yet are nonetheless built upon them.

\section{Acknowledgement}

I thank David Moss for language revision and his insightful comments on this article.

\section{Declaration of Conflicting Interests}

The author(s) declared no potential conflicts of interest with respect to the research, authorship, and/or publication of this article.

\section{Funding}

The author(s) received no financial support for the research, authorship, and/or publication of this article.

\section{Notes}

1. The empirical research was carried out during 8 months between 2008 and 2009 as part of my doctoral thesis.

2. Pallets come in different colours and different sizes. In Europe, however, the standard pallet is $80 \times 120 \mathrm{~cm}$, which fits in trucks and train containers and is also usually considered a standard measure for packaging.

3. It is to be noted that Munn (1986: 268) explicitly maintains that exchange is to be relocated in a more inclusive model of practice. Exchanges are thus only a subset of practices involved in the production or destruction of value. Instead, Strathern (1989: 178-179) uses a very broad definition of exchange and maintains that exchange does not need to involve things. This is what she calls unmediated exchange. For the purpose of this article, however, the distinction is not relevant, since I am only discussing exchanges of specific objects.

4. In a commodity world, notes Strathern (1988: 172) referring to Bourdieu (1972) 'symbolic interests are set against material ones'.

5. My natives were indeed better storytellers than me. They made me interested in all the myths and subtle strategies of pallet exchange, but I was completely unsuccessful in making them interested in kula exchange.

\section{References}

Appadurai A (1986) Introduction: Commodities and the politics of value. In: Appadurai A (ed.) The Social Life of Things: Commodities in Cultural Perspective. Cambridge: Cambridge University Press, 3-63. 
Belk RW (1995) Collecting in a Consumer Society. London: Routledge.

Bevan A (2014) Mediterranean containerization. Current Anthropology 55(4): 387-418.

Bourdieu P (1972) Esquisse d'une théorie de la pratique. Précédé de trois études d'ethnologie kabyle. Genève: Droz.

Breen R (1997) Risk, recommodification and stratification. Sociology 31(3): 473-489.

Carrier JG (1992) Emerging alienation in production: A Maussian history. Man 27(3): 539-558.

Crăciun M (2015) Bobbles and values: An ethnography of de-bobbling garments in postsocialist urban Romania. Journal of Material Culture 20(1): 3-20.

Cross J (2014) The coming of the corporate gift. Theory, Culture \& Society 31(2-3): 121-145.

Dallari F and Marchet G (2010) La gestione dei pallet nella filiera del largo consumo. Available at: http://vecchio.liuc.it/ricerca/clog/cm/upload/opal_definitivo.pdf (accessed 23 July 2016).

Forge A (1972) The Golden Fleece. Man 7(4): 527-540.

Foster RJ (2011) The uses of the use value: Marketing, value creation, and the exigencies of consumption work. In: Zwick D, Cayla J (eds) Inside Marketing: Practices, Ideologies, Devices. Oxford: Oxford University Press.

Foster RJ (2013) Things to do with brands: Creating and calculating value. HAU: Journal of Ethnographic Theory 3(1): 44-63.

Graeber D (2001) Toward an Anthropological Theory of Value. New York: Palgrave.

Graeber D (2014) On the moral grounds of economic relations: A Maussian approach. Journal of Classical Sociology 14(1): 65-77.

Jamieson M (1999) The place of counterfeits in regimes of value: An anthropological approach. Journal of the Royal Anthropological Institute 5(1): 1-11.

Lave J and Wenger E (1991) Situated Learning: Legitimate Peripheral Participation. Cambridge: Cambridge University Press.

Lemon A (1998) Your eyes are green like dollars: Counterfeit cash, national substance, and currency apartheid in 1990s Russia. Cultural Anthropology 13(1): 22-55.

Levinson M (2006) The Box: How the Shipping Container Made the World Smaller and the World Economy Bigger. Princeton, NJ: Princeton University Press.

Malinowski B (1978[1922]) Argonauts of the Western Pacific: An Account of Native Enterprise and Adventure in the Archipelagoes of Melanesian New Guinea. London: Routledge.

Mauss M (2004[1924]) Essai sur le don. Forme et raison de l'échange dans les sociétés archaïques. In: Sociologie et anthropologie. Paris: PUF.

Miller D (2001) Alienable gifts and inalienable commodities. In: Myers FR (ed.) The Empire of Things: Regimes of Value and Material Culture. Oxford: James Currey, 91-115.

Miller D (2008) The uses of value. Geoforum 39(3): 1122-1132.

Munn ND (1977) The spatiotemporal transformations of Gawa canoes. Journal de la Société des océanistes 54-55(33): 39-53.

Munn ND (1983) Gawan kula: Spatiotemporal control and the symbolism of influence. In: Leach JW, Leach ER (eds) The Kula: New Perspectives on Massim Exchange. Cambridge: Cambridge University Press.

Munn ND (1986) The Fame of Gawa: A Symbolic Study of the Value Transformation in a Massim (Papua New Guinea) Society. Cambridge: Cambridge University Press.

Myers FR (2001) Introduction: The empire of things. In: Myers FR (ed.) The Empire of Things: Regimes of Value and Material Culture. Oxford: James Currey, 3-61.

Panella C and Thomas K (2015) Ethics, evaluation and economies of value amidst illegal practices. Critique of Anthropology 35(1): 3-12.

Parker M (2013) Containerisation: Moving things and boxing ideas. Mobilities 8(3): 368-387.

Sahlins M (1976) Stone Age Economics. Chicago: Aldine. 
Strathern M (1988) The Gender of the Gift: Problems with Women and Problems with Society in Melanesia. Berkeley: University of California Press.

Strathern M (1991) One man and many men. In: Godelier M, Strathern M (eds) Big Men and Great Men: Personifications of Power in Melanesia. Cambridge: Cambridge University Press.

Tsing A (2013) Sorting out commodities: How capitalist value is made through gifts. HAU: Journal of Ethnographic Theory 3(1): 21-43.

Urry J (2007) Mobilities. Cambridge: Polity Press.

Weiner AB (1989) Women of Value, Men of Renown: New Perspectives in Trobriand Exchange. Austin: University of Texas Press.

Willis PE (2000) Learning to Labour: How Working Class Kids Get Working Class Jobs. Aldershot: Ashgate.

Zelizer VA (2012) How I became a relational economic sociologist and what does that mean? Politics and Society 40(2): 145-174.

\section{Author biography}

Edda Cecilia Orlandi is a sociologist. She works at the Department of Social and Political Sciences of the University of Milan. Her research interests include consumption, material culture, youth and ethnographic methods. 